\title{
Faktor-Faktor Penumbuh Usaha Mikro-Kecil (UMK) di Wilayah Kota dan Kabupaten Bogor
}

\author{
Ujang Sehabudin ${ }^{1}$ \\ Amiruddin Saleh ${ }^{2}$ \\ Warcito $^{3}$ \\ ${ }^{1}$ Departemen Ekonomi Sumberdaya dan Lingkungan, Fakultas Ekonomi dan Manajemen Institut \\ Pertanian Bogor \\ ${ }^{2}$ Departemen Komunikasi dan Pengembangan Masyarakat, Fakultas Ekologi Manusia Institut \\ Pertanian Bogor \\ ${ }^{3}$ Pusat Pengembangan Sumberdaya Manusia, Lembaga Penelitian dan Pengabdian kepada \\ Masyarakat, Institut Pertanian Bogor
}

\begin{abstract}
Abstrak
Penelitian ini bertujuan untuk mengaji faktor-faktor penumbuh UMK di masyarakat, dengan kasus UMK di wilayah Kota dan Kabupaten Bogor, khususnya UMK yang tergabung dalam Pos Pemberdayaan Keluarga (posdaya). Jumlah responden 100 orang yang tergabung dalam 20 Posdaya, masing-masing 10 Posdaya di Kota Bogor dan 10 Posdaya di Kabupaten Bogor. Responden masing-masing Posdaya berjumlah 5 orang. Penelitian berlangsung dari bulan Juni September 2015. Pendekatan (metode) yang digunakan adalah metode sustainable business, yang terdiri dari aspek sosial (tingkat pendidikan, akses informasi, motivasi, pengalaman usaha, manfaat bagi lingkungan), aspek ekonomi (pemilikan asset/permodalan, akses pembiayaan, askses bahan baku/barang, pemupukan modal, jaringan usaha), dan aspek lingkungan (penanganan limbah, pemanfaatan libah, perijinan/legalitas usaha, penciptaan wirausaha baru), dengan metode analisis menggunakan metode skoring dengan bobot yang seragam untuk setiap aspek dan masing-masing variabel.

Hasil analisis memperlihatkan bahwa faktor-faktor yang mempengaruhi penumbuhan usaha dan bisnis masyarakat adalah faktor sosial, faktor ekonomi, dan faktor lingkungan. Sedangkan dominasi proses dan pola penumbuhan usaha dan bisnis masyarakat di Posdaya dipengaruhi oleh faktor warisan atau turunan. Selanjutnya penumbuhan UMK dipengaruhi oleh motivasi, pengalaman usaha, manfaat bagi masyarakat, pemilikan asset, akses sumber bahan baku, pemupukan modal, jaringan pemasaran, dan penciptaan wirausaha baru. Dalam rangka pengembangan UMK perlu dilakukan pendampingan dan pelatihan bagi pelaku usaha UMK dalam mengakses teknologi, informasi, pasar, dan pembiayaan. Diperlukan upaya untuk meningkatkan motivasi wirausaha di kalangan keluarga dan masyarakat melalui pendampingan, pelatihan dan pemagangan. Fasilitasi pemerintah daerah sangat diharapkan untuk melengkapi aspek perijinan/legalitas usaha dalam meningkatkan dayasaing UMK.
\end{abstract}

Kata kunci: faktor penumbuh usaha, UMK, Posdaya 


\section{PENDAHULUAN}

Pengembangan usaha dan bisnis masyarakat khususnya usaha mikro-kecil (UMK) bertujuan untuk meningkatkan kesejahteraan dan kemandirian masyarakat dengan cara meningkatkan kemampuan pelaku usaha agar mampu memenuhi kebutuhannya sendiri maupun kebutuhan bersama. Proses pengembangan UMK dilakukan melalui peningkatan kapasitas UMK agar dapat menggali potensi masyarakat sehingga dapat maju dan berkembang secara bersama-sama. Proses tersebut akan berjalan efektif jika terlebih dahulu dapat diketahui faktor-faktor yang dapat mendorong pengembangan UMK. Faktor yang merupakan kunci atau prioritas kemudian diperkuat melalui pembinaan, pelatihan, pedampingan, dan fasilitasi lainnya dengan melibatkan seluruh stakeholders terkait, seperti pemerintah daerah, perguruan tinggi maupun dunia usaha. Pengembangan usaha dan bisnis masyarakat berkaitan dengan pengembangan kewirausahaan sosial (Dees, 1998), menyatakan bahwa kewirausahaan sosial merupakan kombinasi dari semangat besar dalam misi sosial dengan disiplin, inovasi, dan keteguhan seperti yang lazim berlaku di dunia bisnis. Kegiatan kewirausahaan sosial dapat meliputi kegiatan: (a) yang tidak bertujuan mencari laba, (b) melakukan bisnis untuk tujuan sosial, dan (c) campuran dari kedua tujuan itu, yakni tidak untuk mencari laba, namun untuk tujuan sosial.

Isu penting dalam pengembangan ekonomi masyarakat adalah melakukan upaya pengembangan kemampuan kewirausahaan yang memadai dan berkelanjutan bagi para pelaku usaha agar mampu mengakses pasar, pembiayaan, akses teknologi dan informasi serta peningkatan manajemen usaha. Tentunya kemampuan wirausaha perlu didukung oleh kemampuan berproduksi, pengolahan, pemasaran dan pengendalian mutu produk serta manajemen yang terkait dengan proses tranformasi pengetahuan dan teknologi (knowledge management). Oleh karena itu, wirausaha perlu memiliki kemampuan dalam mencari dan menangkap peluang usaha sehingga diperlukan upaya memediasi dan memfasilitasi para pelaku 
usaha melalui proses pendampingan konsultasi, fasilitasi dan bimbingan dalam kegiatan usahanya. Disisi lain, model bisnis masyarakat ini perlu keberlangsungan seperti yang dikemukakan oleh Gras, Mosakowski, dan Lumpkin (2011) menyatakan bahwa salah satu topik (dari 27 topik) penelitian kewirausahaan sosial yang penting dan menarik. Model bisnis dan bentuk organisasi sangat berpengaruh terhadap kemampuan perusahaan sosial untuk tumbuh dan berkembang secara berkelanjutan.

Kondisi wirausaha tersebut, umumnya terjadi pada usaha mikro-kecil yang dihadapkan pada berbagai keterbatasan sebagaimana diungkapkan di atas, mencakup akses pembiayaan terhadap lembaga keuangan formal, akses pasar, dan akses teknologi dan informasi. Di samping itu, umumnya produk yang dihasilkan UMK belum terstandardisasi, sangat variatif, dan belum memiliki aspek legalitas seperti perijinan, sertifikasi P-IRT, sehingga daya saing produk relatif rendah dibandingkan produk manufaktur.
Penelitian ini menggali dan mengungkapkan faktor-faktor penumbuh usaha khususnya UMK pada anggota Posdaya di wilayah Kota dan Kabupaten Bogor. Berdasarkan latar belakang dan hasil-hasil penelitian terdahulu mengenai pengembangan UMK (Saleh, A dkk 2014, Muljono dkk 2013, Warcito 2014, Bahtiar, R dkk, 2014, Sadono, D dkk 2013, Saharuddin dkk 2013, Rahmawati 2012, Muljono dkk 2010), maka penelitian tersebut penting dilakukan. Hasil penelitian diharapkan dapat memberikan rekomendasi bagi UMK dan pihak terkait seperti pemerintah daerah, lembaga pembiayaan, dan perguruan tinggi untuk turut serta berpartisipasi mengembangkan UMK sesuai dengan kompetensi dan kewenangan masing-masing.

\section{METODE PENELITIAN}

Penelitian ini dilakukan di wilayah Kota dan Kabupaten Bogor, dengan unit analisis adalah UMK yang tergabung dalam Posdaya. Jumlah responden adalah 100 UMK yang tergabung dalam 20 Posdaya, masing-masing 10 Posdaya di Kota Bogor dan 10 Posdaya di Kabupaten Bogor. 
Jumlah responden untuk masing-masing Posdaya adalah 5 orang. Penelitian berlangsung dari bulan Juni - September 2015. Pendekatan (metode) yang digunakan adalah metode sustainable business, yang mencakup aspek sosial (tingkat pendidikan, akses informasi, motivasi, pengalaman usaha, dan manfaat bagi lingkungan), aspek ekonomi (pemilikan asset/permodalan, akses pembiayaan, askses bahan baku/barang, pemupukan modal, dan jaringan usaha), dan aspek lingkungan (penanganan limbah, pemanfaatan libah, perijinan/legalitas usaha, penciptaan wirausaha baru). Metode analisis menggunakan metode skoring dengan bobot yang seragam untuk setiap aspek dan masing-masing variabel (Tabel $1)$.

Tabel 1. Nilai skoring dan kontribusi masing-masing variabel

\begin{tabular}{|c|c|c|c|c|}
\hline Aspek & Variabel & Skora & Frekuensi $^{b}$ & Total Skor ${ }^{\mathrm{c}}$ \\
\hline \multirow{6}{*}{ Sosial (S) } & 1. Pendidikan (S-1) & & & \\
\hline & 2. Akses informasi (S-2) & & & \\
\hline & 3. Motivasi (S-3) & & & \\
\hline & 4. Pengalaman usaha (S-4) & & & \\
\hline & 5. Manfaat bagi masyarakat (S-5) & & & \\
\hline & Jumlah skor aspek sosial & & & TSS \\
\hline \multirow{6}{*}{ Ekonomi (E) } & 1. Pemilikan asset usaha/modal (E-1) & & & \\
\hline & 2. Akses pembiayaan (E-2) & & & \\
\hline & 3. Akses bahan baku/saprodi (E-3) & & & \\
\hline & 3. Pemupukan modal (E-4) & & & \\
\hline & 4. Jaringan/akses pasarE(S-5) & & & \\
\hline & Jumlah skor aspek ekonomi & & & TSE \\
\hline \multirow{5}{*}{$\begin{array}{l}\text { Lingkungan } \\
\text { (L) }\end{array}$} & 1. Penanganan limbah (L-1) & & & \\
\hline & 2. Pemanfaatan limbah (L-2) & & & \\
\hline & 3. Perijnan/legalitas usaha (L-3) & & & \\
\hline & 4. Penciptaan wirausaha baru & & & \\
\hline & Jumlah skor aspek lingkungan & & & TSL \\
\hline \multicolumn{4}{|c|}{ Total Skor Seluruh aspek } & TST \\
\hline
\end{tabular}

Keterangan :

aSkor : 1=rendah, $2=$ sedang, $3=$ tinggi
${ }^{\mathrm{b}}$ Frekuensi $=$ jumlah responden

${ }^{\mathrm{c}}$ Total skor $=$ skor $\mathrm{x}$ frekuensi 
TSS=total skor aspek sosial;

TSE $=$ total skor aspek ekonomi;

$\mathrm{TSL}=$ total skor aspek lingkungan;

\section{HASIL DAN PEMBAHASAN}

\section{Karateristik Responden}

Mayoritas reponden berada pada kisaran usia 31-50 tahun, usia yang tergolong produktif, dengan mayoritas berpendidikan SLTA dan jenis kelamin perempuan. Responden selain sebagai ibu rumah tangga, umumnya memiliki usaha (wirausaha) sehingga sangat membantu perekonomian keluarga. Jumlah tanggungan keluarga mayoritas 3-4 orang
TST $=$ total skor seluruh aspek $=$ TSS + TSE + TSL

per keluarga. Walaupun mayoritas responden menjadi anggota Pos Pemberdayaan Keluarga (Posdaya), 1-2 tahun, namun jumlah responden yang menjadi anggota Posdaya $\geq 5$ tahun yaitu sejak Posdaya dibentuk (2009) cukup besar. Posdaya bagi responden merupakan wadah atau tempat anggota berkumpul, berkonsultasi dan berdiskusi untuk menyelesaikan permasalahan-permasalahan yang dihadapi oleh anggota termasuk pelaku usaha. Karakeristik responden anggota Posdaya disajikan pada Tabel 2.

Tabel 2. Karakeristik responden UMK anggota Posdaya

\begin{tabular}{|l|l|r|r|}
\hline \multicolumn{2}{|c|}{ Karakteristik } & Jumlah (orang) & Persentasi (\%) \\
\hline \multirow{5}{*}{ Umur (tahun) } & $1-30$ & 10 & 10.00 \\
\cline { 2 - 4 } & $31-50$ & 63 & 63.00 \\
\cline { 2 - 4 } & $51-60$ & 22 & 22.00 \\
\cline { 2 - 4 } & $\geq 61$ & 5 & 5.00 \\
\hline \multirow{5}{*}{ Pendidikan } & SD/MI & 24 & 24.00 \\
\cline { 2 - 4 } & SMP/MTs sederajat & 18 & 18.00 \\
\cline { 2 - 4 } & SMA/MA sederajat & 48 & 48.00 \\
\cline { 2 - 4 } & Diploma 1,2,3 & 2 & 2.00 \\
\cline { 2 - 4 } & Strata 1 & 8 & 8.00 \\
\hline \multirow{5}{*}{ Jenis Kelamin } & Perempuan & 63 & 63.00 \\
\cline { 2 - 4 } & Laki-laki & 37 & 37.00 \\
\hline & 0 & 3 & 3.00 \\
\hline
\end{tabular}

Sumber : diolah (2015) 


\begin{tabular}{|l|l|r|r|}
\multirow{4}{*}{$\begin{array}{l}\text { Jumlah Tanggungan } \\
\text { (orang) }\end{array}$} & $1-2$ & 38 & 38.00 \\
\cline { 2 - 4 } & $3-4$ & 41 & 41.00 \\
\cline { 2 - 4 } & $\geq 5$ & 18 & 18.00 \\
\hline \multirow{3}{*}{$\begin{array}{l}\text { Keanggotaan Posdaya } \\
\text { (tahun) }\end{array}$} & $1-2$ & 44 & 44.00 \\
\cline { 2 - 4 } & $3-4$ & 31 & 31.00 \\
\cline { 2 - 4 } & $\geq 5$ & 25 & 25.00 \\
\hline \multirow{4}{*}{ Pekerjaan utama } & Petani & 11 & 11.00 \\
\cline { 2 - 4 } & Wirausaha & 71 & 71.00 \\
\cline { 2 - 4 } & Karyawan & 1 & 1.00 \\
\cline { 2 - 4 } & PNS/TNI/POLRI & 4 & 4.00 \\
\cline { 2 - 4 } & Tidak bekerja & 4 & 4.00 \\
\cline { 2 - 4 } & Ibu rumah tangga & 9 & 9.00 \\
\hline
\end{tabular}

Mayoritas responden berwirausaha karena faktor turunan atau melanjukan usaha orang tua, mecapai $48 \%$, sedangkan karena factor lainnya adalah lingkungan (28\%) dan motivasi (24\%). Tingginya proporsi faktor turunan ini lebih disebabkan karena keterlibatan responden dalam kegiatan usaha keluarga.

\section{Faktor Penumbuh Usaha}

Penumbuhan usaha UMK anggota Posdaya dalam rangka proses kemandirian usaha dipengaruhi oleh tiga faktor utama, yaitu faktor sosial, faktor ekonomi dan faktor lingkungan. Faktor-faktor tersebut saling bersinergi dan mendorong pengembangan usaha masyarakat. Faktor sosial dipengaruhi oleh tingkat pendidikan, akses terhadap informasi, motivasi, pengalaman usaha dan manfaat bagi masyarakat. Semakin tinggi tingkat pendidikan, semakin baik akses informasi, semakin tinggi motivasi, semakin berpengalaman, dan semakin besar manfaat bagi masyarakat maka keberlanjutan usaha akan semakin terjamin. Motivasi merupakan variabel yang kontribusinya paling tinggi dalam aspek sosial penumbuhan usaha, sedangkan terendah adalah tingkat pendidikan dan akses terhadap informasi. Kontribusi masingmasing variabel sosial disajikan pada Tabel 3. 
Journal of Management Vol.13, No.1, January 2016: 107-121

and Business Review

Tabel 3. Nilai skor dan kontribusi masing-masing variabel sosial

\begin{tabular}{|c|c|c|c|c|}
\hline Variabel & Skor & Frekuensi & Total Skor & Kontribusi (\%) \\
\hline \multirow{4}{*}{ 1. Pendidikan } & 1 & 42 & 42 & \multirow[b]{4}{*}{16.94} \\
\hline & 2 & 48 & 96 & \\
\hline & 3 & 10 & 30 & \\
\hline & \multicolumn{2}{|c|}{ Sub-jumlah } & 168 & \\
\hline \multirow{4}{*}{ 2. Akses terhadap informasi } & 1 & 54 & 54 & \\
\hline & 2 & 22 & 44 & \\
\hline & 3 & 24 & 72 & \\
\hline & \multicolumn{2}{|c|}{ Sub-jumlah } & 170 & 17.14 \\
\hline \multirow{4}{*}{ 3. Motivasi } & 1 & 3 & 3 & \multirow[b]{4}{*}{28.53} \\
\hline & 2 & 11 & 22 & \\
\hline & 3 & 86 & 258 & \\
\hline & \multicolumn{2}{|c|}{ Sub-jumlah } & 283 & \\
\hline \multirow{4}{*}{ 4. Pengalaman Usaha } & 1 & 48 & 48 & \multirow[b]{4}{*}{18.55} \\
\hline & 2 & 20 & 40 & \\
\hline & 3 & 32 & 96 & \\
\hline & \multicolumn{2}{|c|}{ Sub-jumlah } & 184 & \\
\hline \multirow{4}{*}{ 5. Manfaat bagi masyarakat } & 1 & 26 & 26 & \multirow{4}{*}{$\begin{array}{r}18.85 \\
100.00\end{array}$} \\
\hline & 2 & 61 & 122 & \\
\hline & 3 & 13 & 39 & \\
\hline & \multicolumn{2}{|c|}{ Sub-jumlah } & 187 & \\
\hline
\end{tabular}

Sumber: Data primer, diolah (2015)

Tingginya kontribusi variabel umumnya jenis usaha yang dilakukan motivasi ini menunjukkan bahwa respoden adalah kegiatan perdagangan / munculnya wirausaha di masyarakat sangat home industri yang merupakan sektor ditentukan oleh motivasi atau keinginan informal sehingga tidak mensyaratkan kuat dari pelaku yang mau berusaha, pendidikan formal, namun lebih walaupun pengalaman usahanya relatif memerlukan keterampilan teknis yang masih terbatas. Tingkat pendidikan diperoleh melalui pelatihan atau magang. kontribusinya tergolong terendah dalam Oleh karenanya, upaya meningkatkan penumbuhan wirausaha, hal ini karena 
keterampilan teknis UMK merupakan prioritas untuk pengembangan UMK.

Akses informasi termasuk informasi pasar dan harga merupakan variabel yang kontribusinya masih rendah sebagai faktor penumbuh usaha. Hal ini karena secara umum lingkup kegiatan dan target pasar produk UMK responden berada di sekitar tempat tinggal atau lingkungan. Namun demikian dalam rangka pengembangan UMK di masa mendatang, fasilitasi akses informasi ini perlu digalakkan terutama untuk kepentingan informasi pasar dan harga, baik harga sarana produksi maupun harga produk atau jasa yang dihasilkan. Di samping itu, informasi juga dapat berperan dalam pengembangan jaringan usaha.

Kegiatan usaha yang dilakukan responden memberikan manfaat bagi masyarakat sekitar, antara lain penyerapan tenaga kerja dan pemanfaatan sumberdaya/sarana produksi atau bahan baku lokal. Manfaat lainnya adalah mendorong munculnya wirausaha baru, baik di lingkungan keluaga maupun masyarakat. Manfaat usaha bagi masyarakat sekitar ini menempati urutan kedua dari segi kontribusi setelah motivasi. Aspek ekonomi merupakan aspek kedua penumbuh usaha yang mencakup variabel pemilikan asset/permodalan usaha, akses pembiayaan, akses sumber bahan baku/saprodi/barang, pemupukan modal (capital formation), dan jaringan usaha/pemasaran. Semakin tersedia dan atau semakin tinggi akses terhadap kelima variabel tersebut, semakin cepat usaha dapat tumbuh. Variabel yang kontribusinya tertinggi adalah pemilikkan aset/pemodalan. Tingginya kontribusi variabel ini menunjukkan bahwa UMK memerlukan permodalan atau asset yang cukup memadai pada awal mulai usaha, tanpa permodalan awal akan sulit melakukan usaha. Kontribusi masingmasing variabel dalam aspek ekonomi disajikan pada Tabel 4. 
Journal of Management Vol.13, No.1, January 2016: 107-121

and Business Review

Tabel 4. Nilai skoring dan kontribusi masing-masing variabel ekonomi

\begin{tabular}{|c|c|c|c|c|}
\hline Variabel & Skor & Frekuensi & Total Skor & Kontribusi (\%) \\
\hline \multirow{4}{*}{$\begin{array}{l}\text { 1. Pemilikan asset/permodalan } \\
\text { usaha }\end{array}$} & 1 & 11 & 11 & \multirow[b]{4}{*}{23.10} \\
\hline & 2 & 35 & 70 & \\
\hline & 3 & 54 & 162 & \\
\hline & \multicolumn{2}{|c|}{ Sub-jumlah } & 243 & \\
\hline \multirow{4}{*}{ 2. Akses pembiayaan } & 1 & 43 & 43 & \multirow[b]{4}{*}{15.40} \\
\hline & 2 & 51 & 102 & \\
\hline & 3 & 6 & 18 & \\
\hline & \multicolumn{2}{|c|}{ Sub-jumlah } & 162 & \\
\hline \multirow{4}{*}{$\begin{array}{l}\text { 3. Akses sumber bahan } \\
\text { baku/sarana produsi/barang }\end{array}$} & 1 & 26 & 26 & \multirow[b]{4}{*}{20.72} \\
\hline & 2 & 30 & 60 & \\
\hline & 3 & 44 & 132 & \\
\hline & \multicolumn{2}{|c|}{ Sub-jumlah } & 218 & \\
\hline \multirow{4}{*}{$\begin{array}{l}\text { 4. Pemupukan modal (capital } \\
\text { formation) }\end{array}$} & 1 & 22 & 22 & \multirow[b]{4}{*}{22.62} \\
\hline & 2 & 18 & 36 & \\
\hline & 3 & 60 & 180 & \\
\hline & \multicolumn{2}{|c|}{ Sub-jumlah } & 238 & \\
\hline \multirow{4}{*}{ 5. Jaringan pemasaran produk/jasa } & 1 & 49 & 49 & \multirow{5}{*}{$\begin{array}{r}18.16 \\
\mathbf{1 0 0 . 0 0}\end{array}$} \\
\hline & 2 & 11 & 22 & \\
\hline & 3 & 40 & 120 & \\
\hline & \multirow{2}{*}{\multicolumn{2}{|c|}{ Sub-jumlah }} & 191 & \\
\hline Total & & & 1052 & \\
\hline
\end{tabular}

Sumber: Data primer, diolah (2015)

Variabel ekonomi yang pembiayaan perbankan. Dari total kontribusinya terendah adalah akses responden, hanya $11 \%$ yang telah pembiayaan, menunjukkan bahwa pelaku mengakses pembiayaan dari lembaga UMK umumnya menghadapi kendala akses perbankan, yaitu BRI, BJB, BTPN, terhadap pembiayaan terutama sektor Danamon dan BMT atau 17,5\% dari jumlah perbankan, karena terbatasnya atau tidak responden yang mendapatkan pinjaman. adanya jaminan (agunan) sebagai salah satu Sumber pinjaman mayoritas yang dapat persyaratan utama memperoleh diakses responden adalah Koperasi Posdaya 
Indonesia (KPI) yang mencapai 68\% dari jumlah responden yang dapat mengakses pinjaman (Tabel 5).

Oleh karena itu, peningkatan akses pembiayaan yang mudah dan murah mutlak disiapkan pemerintah untuk mendorong pengembangan sektor UMK di masa mendatang, misalnya melalui penyediaan kredit bersubsidi atau kredit tanpa agunan. Jika tidak difasilitasi pemerintah, maka akselerasi pengembangan sektor UMK akan sulit terwujud.

Variabel ekonomi lainnya yang kontribusinya cukup rendah adalah jaringan pemasaran (akses pasar). Produk UMK umumnya dicirikan dengan keragaman kualitas dengan jaminan kesehatan atau keamanan pangan yang masih rendah. Di samping itu seringkali unit cost produk UMK lebih tinggi sehingga sulit bersaing dengan produk manufaktur. Hal ini menyebabkan produk UMK sulit menembus pasar, termasuk pasar tradisional sekalipun. Oleh karena itu, upaya kemitraan dengan pihak lain melalui fasilitasi pemerintah sangat diperlukan untuk membuka jaringan pasar sehingga dapat bersaing dengan produk sejenis yang dihasilkan manufaktur.

Tabel 5. Sumber pembiayaan usaha responden

\begin{tabular}{|c|c|c|c|}
\hline No & \multicolumn{2}{|c|}{ Pembiayaan Usaha } & Jumlah \\
\hline \multirow[t]{2}{*}{1} & \multirow[t]{2}{*}{ Sumber pembiayaan usaha (\%) } & Modal sendiri & 53 \\
\hline & & Pinjaman & 47 \\
\hline \multirow[t]{5}{*}{2} & \multirow{5}{*}{$\begin{array}{l}\text { Lembaga sumber pembiayaan } \\
(\%)\end{array}$} & Bank & 17,5 \\
\hline & & Bantuan program & 4,8 \\
\hline & & Keluarga & 1,6 \\
\hline & & KPI & 66,7 \\
\hline & & Koperasi lainnya & 9,5 \\
\hline \multirow[t]{5}{*}{3} & \multirow[t]{5}{*}{ Besar pinjaman (Rp juta) } & Bank & $2,5-200$ \\
\hline & & Bantuan/kredit program & $25-200$ \\
\hline & & KPI & $0,25-20$ \\
\hline & & Keluarga & 1 \\
\hline & & Koperasi lainnya & $0,25-15$ \\
\hline
\end{tabular}

Sumber: data primer, diolah (2015) 
Terhadap pinjaman pembiayaan dibenahi, walaupun mayoritas responden usaha, jumlah responden yang menyatakan cukup baik. Mengenai mengungkapkan bahwa jumlah realisasi besarnya bunga dan persyaratan pinjaman lebih rendah dari administrasi pinjaman, mayoritas pengajuan/kebutuhan, persentasi mencapai responden menyatakan cukup bahkan 17\%. Demikian pula halnya dengan jangka ringan. Persepsi responden terhadap waktu pinjaman dan lamanya proses pinjaman disajikan pada Tabel 6 . pengajuan sampai realisasi masih perlu

Tabel 6. Persepsi responden terhadap pinjaman

\begin{tabular}{|l|l|r|}
\hline \multicolumn{1}{|c|}{ Aspek Pinjaman } & \multicolumn{1}{c|}{ Penilaian } & \multicolumn{1}{c|}{$\begin{array}{c}\text { Persentasi } \\
(\mathbf{\%})\end{array}$} \\
\hline \multirow{2}{*}{ Kesesuaian Pinjaman } & $\begin{array}{l}\text { Lebih rendah dari } \\
\text { pengajuan }\end{array}$ & 29.31 \\
\cline { 2 - 3 } & Sesuai dgn pengajuan & 70.69 \\
\hline \multirow{3}{*}{ Tanggapan terhadap bunga/jasa } & Berat & 3.45 \\
\cline { 2 - 3 } & Cukup & 24.14 \\
\cline { 2 - 3 } & Ringan & 72.41 \\
\hline \multirow{2}{*}{ Tanggapan terhadap Jangka waktu } & Singkat & 17.24 \\
\cline { 2 - 3 } & Cukup & 60.34 \\
\cline { 2 - 3 } & Lama & 22.41 \\
\hline \multirow{2}{*}{ Tanggapan persyaratan } & Berat & 1.72 \\
\cline { 2 - 3 } & Cukup & 17.24 \\
\cline { 2 - 3 } & Ringan & 81.03 \\
\hline Tanggapan lama pengajuan & Lambat & 22.07 \\
\cline { 2 - 3 } & Cukup & 65.52 \\
\cline { 2 - 3 } & Singkat & \\
\hline
\end{tabular}

Sumber: data primer, diolah (2015)

Faktor penumbuh usaha berikutnya dan penciptaan wirausaha baru. Aspek adalah faktor lingkungan yang mencakup lingkungan saat ini merupakan penanganan limbah, pemanfaatan limbah, pertimbangan khusus terutama dalam pemenuhan aspek legalitas usaha/perijinan, rangka perdagangan produk antar negara. 
Slogan produk ramah lingkungan atau pasar ekspor, seperti CPO untuk memasuki environmental friendly merupakan salah pasar Uni Eropa. Kontribusi masing-masing satu syarat suatu produk untuk memasuki variabel lingkungan disajikan pada Tabel 7.

Tabel 7. Nilai skor dan kontribusi masing-masing variabel lingkungan

\begin{tabular}{|c|c|c|c|c|}
\hline Variabel & Skor & Frekuensi & Total Skor & Kontribusi (\%) \\
\hline \multirow{4}{*}{ 1. Penanganan limbah produksi } & 1 & 67 & 67 & \multirow[b]{4}{*}{25.68} \\
\hline & 2 & 14 & 28 & \\
\hline & 3 & 19 & 57 & \\
\hline & \multicolumn{2}{|r|}{ Sub-jumlah } & 152 & \\
\hline \multirow{4}{*}{ 2. Pemanfaatan limbah } & 1 & 74 & 74 & \multirow[b]{4}{*}{23.48} \\
\hline & 2 & 13 & 26 & \\
\hline & 3 & 13 & 39 & \\
\hline & \multicolumn{2}{|r|}{ Sub-jumlah } & 139 & \\
\hline \multirow{4}{*}{ 3. Perijinan/legalitas usaha } & 1 & 86 & 86 & \multirow[b]{4}{*}{19.26} \\
\hline & 2 & 14 & 28 & \\
\hline & 3 & 0 & 0 & \\
\hline & \multicolumn{2}{|c|}{ Sub-jumlah } & 114 & \\
\hline \multirow{4}{*}{ 4. Penumbuhan wirausaha baru } & 1 & 44 & 44 & \multirow{5}{*}{31.59} \\
\hline & 2 & 25 & 50 & \\
\hline & 3 & 31 & 93 & \\
\hline & \multicolumn{2}{|c|}{ Sub-jumlah } & 187 & \\
\hline Total & & & 592 & \\
\hline
\end{tabular}

Sumber: Data primer, diolah (2015)

Variabel penumbuhan wirausaha tersebut berada. Dengan demikian, baru merupakan variabel yang pengembangan UMK di masyarakat kontribusinya terbesar dalam aspek memerlukan trigger terutama dari pelaku lingkungan dibandingkan variabel lainnya. usaha yang sudah berjalan yang ada di Hal ini mengindikasikan bahwa keberadaan sekitarnya. Jika terdapat pelaku usaha yang UMK dapat mendorong tumbuhnya sukses, maka akan ditiru oleh orang lain di wirausaha baru di lingkungan keluarga atau sekitarnya. Kondisi ini dapat dimanfaatkan sekitar tempat tinggal dimana usaha dengan baik untuk menumbuhkan 
wirausaha baru melalui pemanfaatan atau fasilitasi pelaku usaha yang ada yang sudah terlebih dahulu berjalan melalui pendampingan atau magang.

Sementara itu, perijinan usaha merupakan variabel yang kontribusinya paling rendah. Hal ini dapat dipahami mengingat sektor UMK umumnya merupakan usaha informal yang umumnya merupakan usaha keluarga, sehingga perijinan belum sepenuhnya dipahami dan dilakukan, bahkan mayoritas tidak memiliki ijin, kalaupun ada, hanya sebatas ijin domisili dari desa atau kelurahan. Pelaku usaha UMK selain menganggap belum memerlukan ijin, juga masih beranggapan bahwa proses pengurusan perijinan seperti SIUP, TDP, PIRT dan sertifikat halal, memerlukan waktu dan biaya yang tidak murah. Oleh karena itu, pemerintah daerah melalui SKPD terkait seperti Dinas Perdagangan, Dinas Perindustrian dapat memfasilitasi proses perijinan sektor UMK tersebut. Di samping itu, perlu adanya sosialisasi pentingnya perijinan dalam rangka penjaminan kualitas produk dan pemasaran terutama jika produk dipasarkan di pasar modern bahkan pasar ekspor.

\section{KESIMPULAN DAN SARAN}

\section{Kesimpulan}

Faktor-faktor yang mempengaruhi penumbuhan usaha UMK adalah faktor sosial, faktor ekonomi, dan faktor lingkungan. Motivasi merupakan variabel yang kontribusinya tertinggi terhadap penumbuhan usaha untuk aspek sosial sedangkan variabel pemilikan asset/permodalan untuk aspek ekonomi, dan variabel penumbuhan wirausaha baru untuk aspek lingkungan.

\section{Saran}

Perlunya upaya meningkatkan motivasi wirausaha di kalangan keluarga dan masyarakat melalui pelatihan, pendampingan dan pemagangan dengan melibatkan wirausaha yang ada di sekitarnya. Demikian pula halnya untuk meningkatkan permodalan UKM, diperlukan fasilitasi pemerintah daerah untuk kemudahan akses pembiayaan terhadsap lembaga keuangan melalui kredit. Demikian juga halnya dengan fasilitasi 


\section{Faktor-Fator Penembuh ... (Ujang S., Amiruddin S, dan Warcito)}

pemerintah daerah untuk kemudahan perijinan usaha perlu ditingkatkan.

Perlu dilakukan penelitian lanjutan untuk meningkatkan kapasitas pelaku UKM di bidang penanganan dan pengolahan limbah, peningkatan kemampuan teknis produksi dan manajemen usaha, serta akses pembiayaan dan akses informasi yang lebih komprehensif. 


\section{Daftar Pustaka}

Bahtiar, R dan Warcito. 2014. Peran Tabungan dan Kredit Pundi Sejahtera bagi Keluarga Pra Sejahtera. Prosiding Seminar Nasional Universitas Trilogi, Jakarta.

Dees, G.J. 1998. The meaning of social Entreprenership, Paper, Stanford: Kauffman Center for Entrepreneurial Leadership, Stanford University.

Gras, Mosakowski, Lumpkin. 2011. Gaining Insights from Future Research Topics in Social Entrepreneurship: A Content-Analytic Approach, Emerald Group Publishing Limited, pp.25-50

Muljono P, Burhanuddin, R.Virianita. 2013. Pemetaan Perkembangan Posdaya Untuk Meningkatkan Kualitas Program Pemberdayaan Masyarakat. Laporan Penelitian. Kerjasama Dikti dan IPB. Bogor

Muljono P, Clara M. Kusharto, N. Rochimawati. 2010. Pengembangan Pos Pemberdayaan Keluarga (Posdaya): Upaya Pemberdayaan Masyarakat Lingkar Kampus. Laporan Penelitian Strategis Aplikasi. Kerjasama Dikti dan IPB. Bogor.

Sadono, D, Saharudddin, Yusalina. 2013. Hubungan Pola Pendampingan Dengan Kepuasan Masyarakat terhadap Program Posdaya. Laporan Penelitian. Kerjasama Dikti dan IPB. Bogor

Saharuddin, D. Sadono, R. Virianita. 2013. Respon Masyarakat terhadap Forum Pemberdayaan Masyarakat dengan Model Posdaya. Laporan Penelitian. Kerjasama Dikti dan IPB. Bogor

Saleh, A. Rokhani, R.Bahtiar. 2014. Pengembangan Modal Sosial dan Kewirausahaan melalui Posdaya. Laporan Penelitian. Kerjasama Dikti dan IPB. Bogor

Warcito. 2014. Analisis Strategi Pengembangan Program Pos Pemberdayaan Keluarga (Posdaya) Di Kota Bogor dan Kabupaten Bogor. Jurnal Manajemen Universitas IBN Khaldun, Bogor. Vol 5 No.2/2014. 